\title{
Research on Type Selection of Diving Tower in 110kV Single and Double Circuit Transmission Line
}

\author{
Xinmin $\mathrm{Yu}^{1, *}$, Xiang $\mathrm{Chen}^{1}$, Benzhao $\mathrm{Fu}^{1}$, Yinhe $\mathrm{Lin}^{2}$,Ye Xin ${ }^{2}$ and Ming $\mathrm{Xie}^{2}$ \\ ${ }^{1}$ State GRID Fujian Economic Research Institute, Fuzhou 350000, China \\ ${ }^{2}$ Fujian Yongfu Power Engineering Co.,Ltd, Fuzhou 350000, China
}

\begin{abstract}
With the continuous development of EHV (UHV) transmission lines, new lines often need to drill through the built lines, so it is urgent to study the type of diving towers. Based on typical weather conditions and commonly used ground wire models, the basic type and tower type selection of $110 \mathrm{kV}$ single and double circuit overpass towers in high altitude areas are studied, and two single and double circuit overpass tower schemes are planned and arranged. And according to the pole tower structure design and optimization theory, the $110 \mathrm{kV}$ single-circuit diving tower and the $110 \mathrm{kV}$ dual-circuit diving tower are optimized from the structural optimization layout and the pole tower structure node optimization design. The research results show that the single-circuit diving tower adopts the wine glass tower, and the wires are arranged horizontally, and the double-circuit diving tower effectively reduces the height of the tower. The dish-shaped tower is used, and the single-circuit wires are arranged in a triangle pattern, which provides a certain practical guiding significance for the $110 \mathrm{kV}$ diving-across technology application.
\end{abstract}

\section{Introduction}

In recent years, with the rapid economic development and the acceleration of urbanization, the resources of high-voltage transmission line corridors have become increasingly scarce ${ }^{[1]}$. When new $110 \mathrm{kV}$ lines are drilled for higher voltage lines, it is difficult to choose options, and they are faced with detours, tower upgrades, and double-circuit partial changes. Wait for the situation. At the same time, there are problems such as power outage construction, difficult construction, high overall investment, and inconvenient operation and maintenance.

Reasonable use of diving over towers and diving over high-voltage lines will not increase the length of the line, and it is not necessary to perform power outages on the original high-voltage lines. At the same time, the steel consumption level of the $110 \mathrm{kV}$ line itself will also be reduced, which reduces the project cost and improves the role of economic benefits ${ }^{[2]}$. There is little research on diving towers in China.The design principle of the tower structure is to make the tower meet the lightest weight, beautiful appearance, convenient operation and maintenance, etc. under the premise of meeting the actual conditions of the project. First, the tower must meet the structural requirements and combine the characteristics of the external load. The components of the iron tower bear clear force, direct force transmission, simple node processing, and the cloth material meets its force characteristics. The design of the tower should follow the principles of "safety, reasonableness and economy", which are mainly reflected in the following points: Ensure the strength, stability and necessary rigidity of the tower, as well as future safety; Reduce steel consumption; The components are reasonably arranged, the structure is concise, and the force transmission route is direct, short and clear; The components and inter-nodes are reasonably divided to give full play to the load-bearing potential of the components and optimize the nodes. 2 Design points and precautions. The design of the tower's root opening and tower body opening width The tower body opening width and the value of the tower root opening are related to the change of the tower body slope, which has a huge impact on the overall rigidity and tower weight of the tower. Therefore, choosing the best tower body mouth width and root opening size is one of the key aspects of optimizing the tower design. In addition, the slope of the tower is related to the foundation force and the area occupied by the tower after the tower is built. The smaller the tower slope, the smaller the area occupied, but the greater the foundation force; the greater the tower slope, the greater the foundation force. The smaller, but the larger the area. Therefore, under a certain use condition, there is a suitable range of the size and slope of the upper and lower mouth of the tower. Within this range, the material consumption of the iron tower is the lowest. Because the upper mouth is limited by the electrical clearance, the adjustable range is not Large, under the condition of meeting the electrical clearance, the upper mouth size can be adjusted in a small range, and the lower mouth size can be adjusted in a larger range, and the tower slope and root opening can be optimized by multi-scheme combination. Under the condition of ensuring the overall strength and rigidity of

* Corresponding author: 110903209@qq.com 
the tower, calculate the most reasonable slope and root opening.

As an outstanding technical difficulty, the technology of ultra-high voltage transmission line crossing towers is an outstanding technical problem, and its optimized design and research have very important practical significance for the construction of the transmission line in the Hexi corridor area ${ }^{[3]}$. After the research results are promoted and applied to the lines in the relevant areas, when the newly built $750,3,30 \mathrm{kV}$ lines have to cross the built transmission lines, the crossing point will no longer be a control condition, which can optimize the line path and save money. Line investment $\cos ^{[4]}$.

Therefore, it is very necessary to study the basic type and tower type selection of $110 \mathrm{kV}$ single and double loop diving tower.

\section{Planning conditions of diving tower}

In this paper, the typical meteorological conditions of Gansu Province are selected from the single and doubletrack diving across the tower. The specific meteorological conditions are shown in Table 1.

According to the needs of the project, plan one type of single-circuit and double-circuit tension towers, with a horizontal span of 350 meters, a vertical span of 450 meters, and a maximum span of 550 meters. The number of rotation angles is $0^{\circ} \sim 40^{\circ}$, and the altitude is used. 2500 meters.

For the $110 \mathrm{kV}$ line, referring to the actual situation in the project, it is determined that the conductor uses $1 \times$ LGJ-400/35 steel core aluminum stranded wire, and the ground wire uses GJ-80 steel stranded wire. The safety factor of the wire is 2.5 , and the safety factor of the ground is 3.0 .

Table 1 Tower planning and meteorological conditions.

\begin{tabular}{|c|c|c|c|}
\hline Project & $\begin{array}{c}\text { Temperature } \\
\left.{ }^{\circ} \mathrm{C}\right)\end{array}$ & $\begin{array}{c}\text { Wind } \\
\text { speed(m/s) }\end{array}$ & $\begin{array}{c}\text { Icing } \\
\text { thickness } \\
(\mathrm{mm})\end{array}$ \\
\hline $\begin{array}{c}\text { Maximum } \\
\text { temperature }\end{array}$ & 40 & 0 & 0 \\
\hline $\begin{array}{c}\text { Minimum } \\
\text { temperature }\end{array}$ & -30 & 0 & 0 \\
\hline $\begin{array}{c}\text { Average } \\
\text { temperature }\end{array}$ & 5 & 0 & 0 \\
\hline $\begin{array}{c}\text { Basic wind } \\
\text { speed }\end{array}$ & -5 & 27 & 0 \\
\hline $\begin{array}{c}\text { Operating } \\
\text { overvoltage }\end{array}$ & 5 & 15 & 0 \\
\hline $\begin{array}{c}\text { Lightning } \\
\text { overvoltage }\end{array}$ & 15 & 10 & 0 \\
\hline $\begin{array}{c}\text { Install } \\
\text { Charged } \\
\text { work }\end{array}$ & -15 & 10 & 0 \\
\hline $\begin{array}{c}\text { Icing } \\
\text { thickness }\end{array}$ & -5 & 10 & 0 \\
\hline $\begin{array}{c}\text { Density of } \\
\text { ice(g/cm3) }\end{array}$ & 15 & 0.9 & 10 \\
\hline
\end{tabular}

\section{Planning principles for diving tower}

\subsection{Distance between phases of Conductor}

The horizontal distance between the center wires of the gear pitch is mainly determined by the non-synchronous swing (or dancing) of the wires caused by strong wind, to ensure that the air gap should not be broken down under the normal working voltage. As for the operating overvoltage and lightning overvoltage, the probability that they occur simultaneously with the strong wind and cause the wires to swing (or dance) out of sync is very small, so they are not used as a control condition for determining the horizontal distance between the central wires of the pitch.

\subsection{Cooperate between conductor and ground wire}

The distance between the two ground wires on the tower shall not exceed 5 times the vertical distance between the ground wire and the conductor. In the center of the general span, the distance between the wire and the ground should meet the following formula:

$$
S \geqslant 0.012 L+1
$$

In the formula:

$\mathrm{S}$-the distance between the wire and the ground (m); $\mathrm{L}$ - Gear distance (m);

\subsection{Lightning protection}

The protection angle of the ground wire to the side conductor on the tower, for the $110 \mathrm{kV}$ line, the double circuit or multiple circuit on the same tower is not more than $10^{\circ}$, and the single circuit is not more than $15^{\circ}$. In this design, it is considered not to be greater than $10^{\circ}$.

\section{Type selection of diving tower and tower head planning}

\subsection{Electrical clearance of tower head}

The jumper string in this article uses ordinary diskshaped suspension insulators, which have universal applicability.

According to the planning conditions and planning principles of the diving tower, the wind deflection angle of the jumper string of the diving tower under various operating conditions is calculated, as shown in Table 2:

Table 2 Tower planning and meteorological conditions.

\begin{tabular}{|c|c|c|c|c|}
\hline $\begin{array}{c}\text { Calculation } \\
\text { Working } \\
\text { conditions }\end{array}$ & $\begin{array}{c}\text { Power } \\
\text { frequency }\end{array}$ & $\begin{array}{c}\text { Operated } \\
\text { Voltage }\end{array}$ & $\begin{array}{c}\text { Thunder } \\
\text { and } \\
\text { lightning } \\
\text { Voltage }\end{array}$ & $\begin{array}{c}\text { Charged } \\
\text { Overhaul }\end{array}$ \\
\hline $\begin{array}{c}\text { Wind } \\
\text { declination }\end{array}$ & $53.8^{\circ}$ & $20.3^{\circ}$ & $9.3^{\circ}$ & $9.3^{\circ}$ \\
\hline
\end{tabular}




\subsection{Diving tower of $110 \mathrm{kV}$ single circuit transmission lines}

In order to effectively reduce the height of the tower head and achieve the maximum diving effect, the singleloop diving tower adopts a wine glass tower, and the wires are arranged horizontally, as shown in the figure.

According to the gap circle diagram, the tower head size and structural layout are optimized with the electrical distance as the limiting condition. The tower head layout size is shown in the figure.

1)Distance between phases of Conductor

The planning result is: the wires are arranged horizontally, and the distance between the wires is $5.4 \mathrm{~m}$. From the content of the tower head planning principle above, in the case of the maximum use span, the minimum required distance between the conductors is $4.14 \mathrm{~m}$. Therefore, the distance between the conductors of the diving tower is designed to meet the requirements.

2)Cooperate between conductor and ground wire

According to the planning result, the distance between the two lightning protection lines is $\mathrm{m}$. See the table below for the ground wire coordination results:

Table 3 The result of cooperation between conductor and ground wire.

\begin{tabular}{|c|c|c|c|c|c|}
\hline $\begin{array}{c}\text { Span } \\
/ \mathrm{L}\end{array}$ & $\begin{array}{c}\text { Ground } \\
\text { wire } \\
\text { height }\end{array}$ & $\begin{array}{c}\text { Sag of } \\
\text { Conductor }\end{array}$ & $\begin{array}{c}\text { Sag of } \\
\text { Ground } \\
\text { wire }\end{array}$ & $\begin{array}{c}\text { vertical } \\
\text { distance }\end{array}$ & $\begin{array}{c}0.012 \\
\mathrm{~L}+1\end{array}$ \\
\hline 200 & 2.5 & 3.76 & 1.73 & 4.53 & 3.4 \\
\hline 250 & 2.5 & 5.44 & 2.64 & 5.29 & 4.0 \\
\hline 300 & 2.5 & 7.42 & 3.73 & 6.19 & 4.6 \\
\hline 350 & 2.5 & 9.78 & 5.14 & 7.15 & 5.2 \\
\hline 400 & 2.5 & 12.63 & 6.92 & 8.20 & 5.8 \\
\hline 450 & 2.5 & 15.84 & 9.00 & 9.35 & 6.4 \\
\hline
\end{tabular}

It can be seen from the values in the table that the distance between the two ground wires meets the requirements, and the distance between the center wire of the pitch and the ground wire meets the requirements.

3)Lightning protection

(1) The steel tower design lightning protection angle is $10^{\circ}$.

(2) Protection of the ground wire to the edge phase.

(3) Protection of the earth wire to the neutral phase.

Taking into account the difference of the angle steel guideline at the hanging point of the guide and the ground wire, and leaving a certain margin, at the same time, consider the requirement of minimizing the size of the tower head. Based on the above factors, the height of the ground wire support is determined to be $2.5 \mathrm{~m}$, which meets the design requirements at this time.

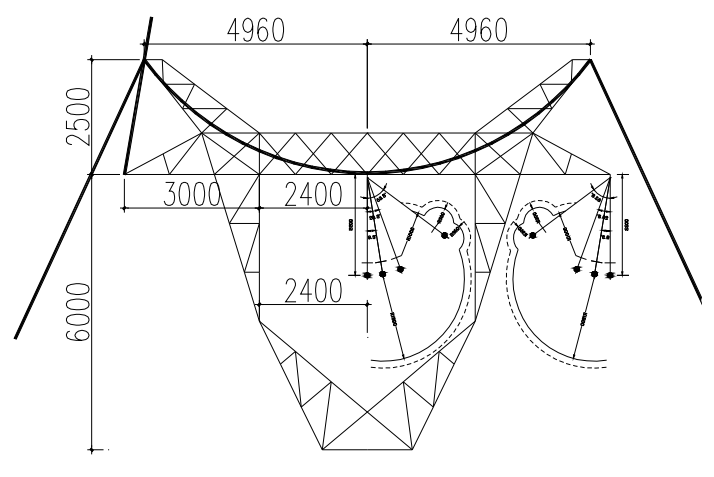

Fig. 1. Tower head planning and layout and ground wire lightning protection.

\subsection{Undercrossing steel tower of $110 \mathrm{kV}$ double loop transmission lines}

In order to effectively reduce the tower height, the double-circuit diving over the tower adopts a dishshaped tower, and the single-circuit conductors are arranged in a triangle pattern, as shown in the figure.

According to the gap circle diagram, with the electrical distance as the limiting condition, optimize the layout of the tower head size. The layout size of the tower head is shown in the figure.

1)Distance between phases of Conductor

The planning result is: adopt double circuits on the same tower, single circuit conductors are arranged in a triangle pattern, the horizontal distance between the lower conductors is $4.3 \mathrm{~m}$, and the equivalent horizontal distance between the upper conductor and the lower conductor is calculated by the formula:

$$
\mathrm{D}_{\mathrm{X}}=\sqrt{\mathrm{D}_{\mathrm{P}}^{2}+\left(4 / 3 \mathrm{D}_{\mathrm{z}}\right)^{2}}=\sqrt{0.8^{2}+(4 / 3 ? 3.8)^{2}}=5.13 \mathrm{~m}
$$

Between different circuits, the minimum value of the distance between the conductors is $7 \mathrm{~m}$. Therefore, the distance between the conductors of the diving tower is designed to meet the requirements.

2)Cooperate between conductor and ground wire

According to the planning result, the distance between the two lightning protection lines is $\mathrm{D}=13.6 \mathrm{~m}$. See the table below for the ground wire coordination results:

Table 4 The result of cooperation between conductor and ground wire.

\begin{tabular}{|c|c|c|c|c|c|}
\hline $\begin{array}{c}\text { Span } \\
\text { /L }\end{array}$ & $\begin{array}{c}\text { Ground } \\
\text { wire } \\
\text { height }\end{array}$ & $\begin{array}{c}\text { Sag of } \\
\text { Conductor }\end{array}$ & $\begin{array}{c}\text { Sag of } \\
\text { Ground } \\
\text { wire }\end{array}$ & $\begin{array}{c}\text { vertical } \\
\text { distance }\end{array}$ & $\begin{array}{c}0.012 \mathrm{~L} \\
+1\end{array}$ \\
\hline 200 & 2.3 & 3.76 & 1.73 & 4.33 & 3.4 \\
\hline 250 & 2.3 & 5.44 & 2.64 & 5.09 & 4.0 \\
\hline 300 & 2.3 & 7.42 & 3.73 & 5.99 & 4.6 \\
\hline 350 & 2.3 & 9.78 & 5.14 & 6.95 & 5.2 \\
\hline 400 & 2.3 & 12.63 & 6.92 & 8.00 & 5.8 \\
\hline 450 & 2.3 & 15.84 & 9.00 & 9.15 & 6.4 \\
\hline
\end{tabular}

It can be seen from the values in the table that the distance between the two ground wires meets the 
requirements, and the distance between the center wire of the pitch and the ground wire meets the requirements.

3)Lightning protection

(1) The steel tower design lightning protection angle is $10^{\circ}$.

(2) Protection of the ground wire to the edge phase.

(3) Protection of the earth wire to the neutral phase.

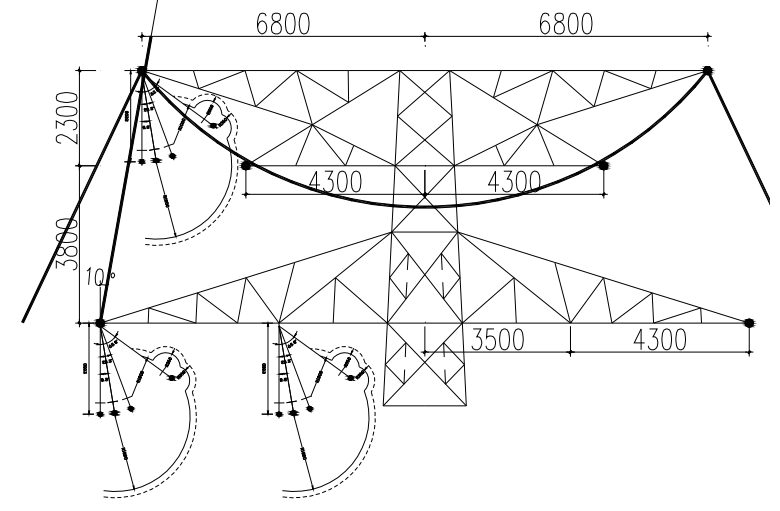

Fig. 2. Tower head planning and layout and ground wire lightning protection

The position changes of the lowest point $\mathrm{O}$ corresponding to different ground wire support heights are shown in the following table:

Table 5 The position change of the lowest point $\mathrm{O}$ corresponding to different ground wire bracket heights.

\begin{tabular}{|c|c|c|c|c|c|}
\hline Gh & $\mathrm{D} / 4 \mathrm{P}$ & $\mathrm{Hp}$ & $\mathrm{S} l$ & $\mathrm{Gh}+\mathrm{Sl}$ & Is it satisfied \\
1.8 & 3.4 & 2.24 & 0 & 1.8 & No \\
1.9 & 3.4 & 2.24 & 0 & 1.9 & No \\
2 & 3.4 & 2.24 & 0 & 2 & No \\
2.1 & 3.4 & 2.24 & 0 & 2.1 & No \\
2.2 & 3.4 & 2.24 & 0 & 2.2 & No \\
2.3 & 3.4 & 2.24 & 0 & 2.3 & Yes \\
2.4 & 3.4 & 2.24 & 0 & 2.4 & Yes \\
2.5 & 3.4 & 2.24 & 0 & 2.5 & Yes \\
\hline
\end{tabular}

Gh-Ground wire height

Sl-String length

Hp-Equivalent protection height of mid-phase hanging point

It can be seen from the above table that the height of the ground wire support should be designed to be at least $2.3 \mathrm{~m}$ in order to make the conductor phase within the lightning protection range of the ground wire.

\section{Conclusion}

This paper takes the typical weather conditions of Gansu Province and the $110 \mathrm{kV}$ typical ground wire model as the research object. Through the selection analysis, planning and design of $110 \mathrm{kV}$ single-circuit and doublecircuit overpass towers, the $110 \mathrm{kV}$ single-circuit winecup overpass tower and $110 \mathrm{kV}$ double-circuit butterfly type diving tower.
The research results show that the single-circuit diving tower adopts the wine glass tower, and the wires are arranged horizontally, and the double-circuit diving tower effectively reduces the height of the tower. The dish-shaped tower is used, and the single-circuit wires are arranged in a triangle pattern.

The two tower types have reasonable structural layout, safe and reliable technology, good economic and social benefits, and provide reference and guidance for the planning, design and application of diving towers.

\section{Acknowledgments}

The project was funded by Consulting Specific Fund of the State Grid Fujian Electric Power Co., Ltd. (Fund Name: Deepen Application Research Technology of $110 \mathrm{kV}$ Pole and Tower Universal Design Module).

\section{References}

1. Code for design of $110 \mathrm{kV} \sim 750 \mathrm{kV}$ overhead transmission line: GB50545-2010. China Construction Industry Press, 2010.

2. Song Yan, Wang Wei, Wang Hui. (2012) Scheme Selection of $220 \mathrm{kV}$ Double-circuit Transmission Line Undercrossing $500 \mathrm{kV}$ Transmission Line. Electric Power Construction, 33:89-93.

3. Overvoltage protection and insulation coordination for AC electrical installations: DL/T 6201997 .China Electric Power Press, 1997.

4. Power system overvoltage calculation, Shi Wei, Guo Jie, [M], Higher Education Press, Bei Jing, 2006. 